\title{
On the Strategies to Cultivate College Students' Autonomous English Learning Ability in the New Era
}

\author{
Guoqiao Wang ${ }^{1} \&$ Ligang Han $^{2}$ \\ ${ }^{1 \& 2}$ English Department, North China Electric Power University, Baoding City, Hebei Province, China \\ Correspondence: Guoqiao Wang, English Department, North China Electric Power University, Baoding City, \\ Hebei Province, China.
}

Received: September 29, 2020

Accepted: October 23, 2020

Online Published: October 27, 2020

doi: 10.5539/elt.v13n11p94

URL: https://doi.org/10.5539/elt.v13n11p94

\begin{abstract}
The cultivation of students' autonomous learning ability is one of the significant and essential tasks of college English teaching. In this paper, the current situation of college students' insufficient autonomous English learning ability is thoroughly analyzed. Some effective and feasible strategies to cultivate students' autonomous English learning ability are put forward based on the factors that influence this ability. Interaction, continuous thinking, cultural introduction and a good network environment are indispensable to develop and enhance this autonomous learning ability.
\end{abstract}

Keywords: strategies, cultivate, college students, autonomous, English learning ability, new era

\section{Introduction}

Cultivating autonomous learning ability is the need of social development in this new era since we are confronted with a great number of unprecedented challenges, such as the fantastic development of science and technology, the frequent change of career, and the fast speed and high frequency of knowledge update. It cannot be denied that, in order to possess the competence of lifelong learning, learners need to learn how to learn, which is the autonomous learning ability. Therefore, cultivating the autonomous learning ability in the process of teaching English as a foreign language has become a basic educational requirement and goal, which is also the essence of teaching and learning in the education field.

\section{Literature Review}

There have been numerous researches conducted overseas on learning strategy training since 1980s. Cohen \& Aphek (1980) trained students on memorizing new words by the way of association. Bialystok (1983) trained students on guessing the meaning of new words in context. Wenden (1982) and Nunan (1997) achieved remarkable accomplishments on the training of meta-cognition strategy. O 'Malley (1987) and Oxford (1990) focused on the the integrated training of meta-cognition strategy, cognition strategy and emotional strategy. Compared with foreign countries, domestic research on autonomous learning strategy training started much later. And it began to develop gradually from 1990s. There are twelve empirical study papers published on core journals in domestic and foreign languages and education from 1995 to 2003. Ji Kangli (2002) published a paper on meta-cognition strategy training. Eight papers are written about the training of cognition strategy, among which three papers are about listening strategy training (Lv Changhong, 2001; Zhou Weijing, 2002; Su Yuanlian, 2003). Two papers are focused on reading strategy training (Meng Yue, 2004; Xia Zhanghong, 2006). The paper written by Li Li (2004) is about writing strategy training. And Wang Lifei wrote a paper on the topic of oral communication strategy training. From the above literature review, we can find that there has been inadequate research on the training of students' autonomous learning ability, especially under the circumstance of Internet and multi-media in the new era. There's no denying that it's of vital significance to cultivate students' autonomous ability in English learning as a foreign language. This paper intends to make a thorough analysis of the strategies to cultivate students' autonomous learning ability when they learn English as a foreign language. I hope this paper can show some enlightenment and contribution to College English teaching.

\section{Features of Autonomous Learning Ability}

Based on researchers' findings, the features of autonomous learning ability can be summarized as follows: Learners are ready to be responsible for their own learning; Learners supervise the pace of their learning; 
Learners decide the direction of their own learning; Learners evaluate the outcome of their own learning; Learners reflect on their learning to improve their learning efficiency. (Shi, 2016) Students with autonomous learning ability can take the initiative to set their goals, make a clear study plan, select skills and methods to be used, monitor the procedure of acquisition properly and evaluate what they have learned. They are active participants in the social process of classroom learning.

\section{Key Factors Affecting Autonomous Learning Ability}

The ultimate purpose of language teaching and learning is to learn how to communicate with people from other cultures effectively, how to become the master of learning, as well as how to nurture an autonomous learner for lifelong learning. Meanwhile, mastering and applying effective learning strategies is one important and dominant component in cultivating autonomous learning ability. It's generally acknowledged that cultivating students' autonomous learning ability is of vital significance. Hence it's of great importance to analyze the key factors that affect autonomous learning ability.

Achieving learner autonomy is conditioned by various internal factors like intelligence, motivation, learning strategies as well as external factors like learning environment, teachers, educational system, etc. Among these variables, some factors such as intelligence and educational system are relatively stable and not readily amenable. Here we only discuss the following four factors for the reason that they exert direct influence on learning outcomes and autonomous language learners can control these elements to achieve successful language learning.

\subsection{Learners' Attitude}

Learners' attitude plays an important role in the cultivation of autonomous learning ability. Learners' attitude means whether she/he is willing to take responsibility for his/her own study. Learners' active attitude is the first step to move into autonomous learning. It is affected by four main elements: teachers, the educational system, peers and the society. Among these factors, teachers have dominant influence because they introduce, advocate and promote autonomy. (Benson, 2005) With an enthusiastic attitude, teachers emphasize and encourage students to study with autonomy. Then students are more likely to develop an awareness of autonomous learning. Since educational institution is responsible for making the policy, institutional support becomes important when funding is required for the resources of autonomous learning. Important influence may come from their peers. If some groups of students have successfully used autonomous learning, other students are likely to have a try. Societal factors including parental pressure, culture and power hierarchies can also have important impact on autonomous learning.

\subsection{Learners'Motivation}

Motivation is defined as the factors that contribute to a person's desire to do things. As far as the relationship between motivation and autonomy is concerned, learner autonomy increases motivation, which enhances their learning effectiveness. (Li, 1999) Motivation can be promoted by encouraging students to exercise personal control in the course of learning and to be responsible for it. Therefore, motivation is indispensable for facilitating autonomy.

It is vital for teachers to inspire students' motivation because motivation determines students' attitudes towards learning and plays a decisive role in the whole learning process and their learning outcome is determined by this. Thus, motivated study is a premise for initiating autonomous learning. And a motivated learner is likely to accept autonomous learning more easily than less-motivated learners.

\section{Strategies to Cultivate Students' Autonomous Learning Ability}

\subsection{Increasing Students' Awareness of Language Learning Strategy}

With the increasing popularity of autonomous learning, the mastery and application of various language learning strategies are of vital importance. Students' autonomous learning ability can be developed through learning strategy training. First of all, language learning strategies need to be clearly defined and classified. A learning strategy is a particular mental process of gathering, processing, relating, grouping, practicing and locating information to develop regular skills. Learning strategies are specific problem-oriented techniques that learners adopt to facilitate learning process. (O’Malley \& Chamot, 2001) Language learning strategies are especially important to college students since feasible and effective learning strategies may result in improved performance and more self-confidence during language learning and language use. Students' awareness of language learning strategies should be cultivated and enhanced. As language learners, students need to consciously or unconsciously explore and find out their favorite strategies to adopt in the learning process. Teachers should lay more emphasis on language learning strategies. The students should be able to internalize strategic mechanisms to cope with the learning environment an apply these strategies flexibly. English teachers should be aware of 
students' strategy preferences, usage and needs so as to be able to facilitate the language learning process more effectively. In addition, teachers should encourage and motivate students to adopt various learning strategies to accomplish various learning tasks.

Given the importance of learning strategies, considerable researches have been conducted. The strategies to cultivate students' autonomous English learning ability have been explored and studied for decades by researchers and teachers. Quite a few strategies such as meta-cognitive strategies, cognitive strategies, resource strategies, communicative strategies have been proved and agreed to be feasible and effective. (Jiang, 2010) Cognitive strategies refer to the process and behaviors which learners apply to help them improve their ability to learn or remember something, particularly those skills which learners use to accomplish specific classroom tasks and activities. Cognitive strategies are more limited to fulfill specific learning tasks and deal with the received information, utilizing it in ways that strengthen learning, such as repeating, inducing, deducing, transferring, questioning, etc.

Meta-cognitive strategies are higher skills to carry out orders that may involve monitoring, making plans, or self-evaluating the outcome of a learning activity. They refer to making plans for learning, reflecting on the learning process, monitoring the output or understanding, and assessing learning after the fulfillment of an activity. (Gardner \& Miller, 1999) At the planning stage, the learner sets his/her own goals and decides the steps to achieve the goals. At the monitoring stage, the learner observes and monitors his/her learning process. At the evaluating stage, the learner assesses the result of using certain strategies. Students without meta-cognitive approaches are essentially learners without direction or opportunities to design their learning, take charge of their progress, or reflect on the learning effect and establish proper directions for their future learning.

\subsection{Improving Learning Environment}

Language learning environment is a crucial factor affecting autonomous learning. Most important of all is the classroom atmosphere. The traditional teacher-centered learning environment emphasizes operation and reinforcement for transferring knowledge. Under such teaching mode, there is little student autonomy in the learning process, which results in students' low motivation and passive attitude in English learning. In view of the fact that formal classroom learning is still the dominant environment for foreign language teaching, it's necessary and urgent to establish a supportive self-access language learning environment. (Ren, 2013)

Secondly, language-using environment is a practical problem that has to be confronted and taken into consideration. Since most students are immersed in their native language and separated from the English environment, they rarely have chances to communicate with native speakers. As they can't experience the feeling of accomplishment that comes from putting the language into use, they consider it irrelevant and show little interest in learning.

The last obstacle concerning autonomous learning is the social environment in which students live. Language learners are not isolated and they are definitely influenced by lots of distractions in their social life. They may have more interests in other aspects rather than language learning. Besides, there are many other external factors such as teachers, teaching facilities, classroom conditions, available resources and the size of classes etc.

Therefore, language learning environment need to be improved so that students' enthusiasm and motivation can be inspired. More opportunities should be offered to them to practice using the language.

\subsection{Embedding Strategy Training into Language Tasks}

Teachers should embed strategy training into teaching content. Strategy-based instruction should be integrated directly into the classroom teaching. While designing language tasks, teachers should include strategy training so that students can get accustomed to absorbing both the language content and the learning strategies simultaneously. (McDevitt, 1997)

Besides, English teachers should constantly improve their teaching methods and update teaching styles. They should also check whether their teaching plans can give students sufficient chances to apply a variety of learning strategies in different ways.

\subsection{Select Network Resources Correctly}

With the remarkable development of digital technology and the Internet, people have easy access to information. Abundant and numerous resources are available on the Internet. Surrounded by abundant English learning resources, students with learning autonomy have the awareness to select proper learning materials and sort out the needed information. Thus, students are able to pick out favorable online resources based on their specific learning purposes. Take oral English as an example, if students prefer British English, they can get access to 
original English programs such as BBC to imitate British pronunciation. (Shen, 1993) Meanwhile, coupled with their acquired knowledge and learning ability, students with learning autonomy should make some adjustment after comprehending the knowledge they have obtained.

\section{Extending Teachers' Role in Language Teaching}

Most students take a positive attitude towards autonomous learning yet don't know what to learn and how to learn. So it is the teachers' responsibility to guide and instruct them into autonomous learning. As we are promoting learner autonomy and learner responsibility, the role of the teacher should be emphasized, especially at the initial stage of autonomous learning, when students are still inexperienced and immature, and cannot do without teacher's guidance. Teachers are expected to assume a range of overlapping roles: instructor, needs analyst, curriculum developer, materials developer, activity organizer, strategy trainer, motivator and facilitator of independent learning. Teachers should encourage students to explore various models of autonomous learning by themselves. At the same time, teachers should provide students with abundant learning materials and create favorable atmosphere for them to learn autonomously. What's more, teachers can guide students to solve problems during the autonomous learning through cooperative study, such as team-work and group discussion. (Oxford, 1990) Above all, the most important task of teachers is to guide the students from a relatively passive teacher-dependent role to become a more independent, confident learner with the awareness of autonomous learning.

\subsection{Five Steps in Implementing Learning Strategies Instruction}

When teachers teach language learning strategies, they can resort to two approaches which are direct and embedded. Learning strategy can be directly instructed to students. Adequate training is suggested to inform the students of the significance and benefits of learning strategies; Embedded training means that the application of learning strategies is integrated into the teaching process but not directly explained to students. (Macaskill, 2010) Of all the patterns of learning strategy instructions, perhaps O' Malley and Chamot's Cognitive Learning Approach has the widest influence. Concluded from their empirical researches, this model combines learning strategy instruction with content topics and language development activities. In this model five steps are involved, that is, preparation, presentation, practice, evaluation and expansion activities. A brief introduction of each step is as follows.

(1) Preparation

In the first step of preparation, teachers find out what students really know about the content and strategies, what weak points in previous knowledge need to be reinforced, and how students have been instructed to get involved in learning activities or tasks. Elaboration, organization and optional attention are commonly instructed and applied in the preparation stage.

(2) Presentation

In the presentation stage, teachers present and explain new knowledge and information to students in English with necessary clues. The key point is that teachers need to make sure that students can accurately understand the new information so that they will be able to utilize it effectively in the next step. Strategies such as self-monitoring, elaboration, and positive inference may be taught.

(3) Practice

As students engage in practicing new information exposed in the presentation period, it is generally student-centered, and teachers act as facilitator and adviser to help students absorb the new information and apply strategies in effective ways. Similarly, some learning strategies are practiced in this stage: planning, elaboration, cooperation, self-monitoring, summarizing, deduction.

(4) Evaluation

In the period of evaluation, students evaluate the quality of their performance so that they can well master what they have learned and what needs to be reviewed. Evaluation can be directed by teachers. Individual and cooperative approaches are also effective.

(5) Expansion activities

This step provides students with rich and various chances to comprehend and digest the new concepts and skills they have learned. They can further combine them with their acquired knowledge framework and apply them in their daily study. Students may also be given opportunities to exercise higher order thinking skills and combined learning strategies appropriate to activities. 
Based on cognitive theory, this five-step pattern integrates language strategy instruction into linguistic development. This pattern includes both teacher-directed and student-centered activities. The distinctive feature of the pattern is the incorporation of the identification and training of learning strategies. Thus, learners are exposed specific applications of the learning strategies and are likely to transfer learned strategies to new tasks and situations.

\subsection{Implementing Strategy-Based Classroom Instruction}

Mastering learning strategies is vital to cultivate students' autonomous ability, which is beneficial to their lifelong learning and development. Since college English class in China has been teacher-oriented for a long time, language teaching should be shifted from a teacher-directed approach to a learner-centered one. The current shift, along with the need to promote learner autonomy has resulted in new challenges for English teachers. Therefore, it is necessary for teachers to change their attitude and be fully aware of their responsibility to promote students' autonomous learning ability. (Lee, 2009)

\subsection{Enhance Interaction}

Internet has become popular and offers accessible interaction platforms for students, Taking advantage of new media, students can make use of network learning tools to communicate with their peers and the teachers. To some extent, peers can help arouse students' learning interest and get students involved in cooperative learning. For instance, students with the same interest or goal can join in and form English study forums. Regular activities can be organized for them to exchange learning methods and experiences. In these activities, they learn from each other and encourage each other. Mutual encouragement can help enhance their awareness of self-discipline. On the other hand, English teachers bear the responsibility to guide and inspire students to strengthen their autonomous English learning. (Lier, 1996) Specialized lectures need to be opened to introduce learning strategies and proper selection of online learning resources. Meanwhile, it's suggested that teachers have active interaction with students. Adequate and enough interaction with students enable teachers to learn about students' particular needs and their problems. By doing this, timely help can be offered to students.

\subsection{Lay Emphasis on Continuous Learning}

In the modern network era of "Fast-food Culture", college students are greatly influenced and they are accustomed to accepting segmented and fractional information instead of those systematic profound knowledge. Some students practice autonomous learning strategy just to complete teachers' homework, pass tests. In depth, they lack adequate internal motivation. Some students may lack enough patience and endurance to improve their autonomous learning ability, and unwilling to spend enough time on autonomous learning. (Ke, 2016) The significance and advantages of autonomous learning needs to be emphasized and conveyed to students. Teachers need to lay enough emphasis on the continuity of autonomous learning. The biggest advantage of autonomous learning is to establish learners' dominant position. By means of continuous learning and autonomous study, students can understand and accomplish their English courses with satisfactory result. It's recommended that students keep autonomous learning up even after graduation and make it a lifelong learning style.

\subsection{Enhance Students' Cultural Awareness}

Students' insufficient knowledge of foreign culture may affect their interest in learning the language. So it's imperative to enhance students' cultural awareness. Language is the carrier of culture. To master a foreign language, it's imperative to learn about its culture. Lack of relevant cultural knowledge will not only limit Chinese students' learning motivation, but also restrict the effect and competence of language acquisition. Introducing more culture of English speaking countries will help students understand English language better, add more fun to language study and arouse students' interest. Internet at present is the dominant medium around the world to spread and learn about culture, especially in the new era of modern media, where students can use their mobile phones to get access to English news and articles, watch TV series and movies of English-speaking countries to get familiar with foreign culture. Therefore, enhancing students' cultural awareness plays an indispensable role in the course of learning English as a foreign language.

\section{Conclusion}

To sum up what has been discussed above, it's of vital significance to cultivate students' autonomous ability in English learning as a foreign language. This autonomous ability can promote the overall development of the students. The cultivation of this ability depends on the common efforts of the school authority as well as teachers and students. Teachers shoulder the great task of implementing effective strategies to cultivate students' autonomous English learning ability. Only by integrating strategy instruction into the whole process of learning and teaching, can students be better aided to cultivate their learning autonomy, thus establishing a solid 
foundation for the general development of the students.

\section{Acknowledgments}

This paper is supported by 'the Fundamental Research Funds for the Central Universities (Grant No. 2020FR007)'.

\section{References}

Benson, P. (2005). Teaching and Researching Autonomy in Language Learning. Beijing: Foreign Language Teaching and Research Press.

Gardner, D., \& Miller, L. (1999). Establishing Self-access: from theory to practice. Cambridge: Cambridge University Press. https://doi.org/10.1016/S0346-251X(00)00004-X

Jiang, W. J. (2010). The necessity of college students' autonomous learning based on network environment and the analysis of learning status. Overseas English, 7, 108-109.

Ke, Xixiang. (2016). On Cultivating Autonomous Learning Ability for University Students Based on Web. Theory and Practice in Language Studies, 6(9), 17-20. https://doi.org/10.17507/tpls.0609.11

Lee, Jerome. (2009) Ways of learning: learning theories and learning styles in the classroom. European Journal of Teacher Education, 33(2), 219-221. https://doi.org/10.1080/02619760903499646

Li, Ming. (1999). Learner Autonomy and the Need for Learner Training in ELT in China. Teaching English in China, 01, 3-5.

Lier, Van L. (1996). Interaction in the Language Curriculum, Awareness, Autonomy and Authenticity. New York: Longman. https://doi.org/10.2307/3588055

Macaskill, A., \& Taylor, E. (2010). The development of a brief measure of learner autonomy in university students. Studies in Higher Education, 35(3), 351-359. https://doi.org/10.1080/03075070903502703

McDevitt, B. (1997). Learner Autonomy and the Need for Learner Training. Language Learning Journal, 16(1), 34-39. https://doi.org/10.1080/09571739785200251

O’Malley, J. M., \& Chamot, A. U. (2001). Learning Strategies in Second Language Acquisition. Shanghai: Shanghai Foreign Language Education Press.

Oxford, R. L. (1990). Language Learning Strategies: What Every Teacher Should Know. New York: Newbury House Publisher. https://doi.org/10.2307/3586958

Ren, Yongdong. (2013). The Design and Implementation of Web-Based Autonomous English Learning Platform. Advanced Materials Research, 850-851, 681-684. https://doi.org/10.4028/www.scientific.net/AMR.850-851.681

Shen, Weimin. (1993). Discovery as autonomous learning from the environment. Machine Learning, 12, 143-165. https://doi.org/10.1007/BF00993064

Shi, Xianhong. (2016). Analysis of College Students' Autonomous Learning Ability and Self Cultivation Based on Network Environment. China Modern Educational Equipment, 19, 29-32.

\section{Copyrights}

Copyright for this article is retained by the author(s), with first publication rights granted to the journal.

This is an open-access article distributed under the terms and conditions of the Creative Commons Attribution license (http://creativecommons.org/licenses/by/4.0/). 